\section{- OPEN ACCESS}

\title{
Sexual relationships, intimate partner violence and STI partner notification in Cape Town, South Africa: an observational study
}

\author{
Catherine Mathews, ${ }^{1,2}$ Moira 0 Kalichman, ${ }^{3}$ Ria Laubscher, ${ }^{4}$ Cameron Hutchison, ${ }^{1}$ \\ Koena Nkoko, ${ }^{5}$ Mark Lurie, ${ }_{1}^{6}$ Seth C Kalichman ${ }^{3}$
}

${ }^{1}$ Health Systems Research Unit, South African Medical Research Council, Cape Town, South Africa

${ }^{2}$ School of Public Health and Family Medicine, University of Cape Town, Cape Town, South Africa

${ }^{3}$ Department of Psychology, University of Connecticut, Storrs, Connecticut, USA

${ }^{4}$ Biostatistics Unit, South African Medical Research Council, Tygerberg, South Africa ${ }^{5}$ City of Cape Town Health Department, Cape Town, South Africa

${ }^{6}$ Brown University School of Public Health, Providence, Rhode Island, USA

\section{Correspondence to} Dr Catherine Mathews, Health Systems Research Unit, South African Medical Research Council, Tygerberg, 7505, South Africa; cathy.mathews@mrc. ac.za

Received 8 October 2017 Accepted 11 November 2017 Published Online First 30 November 2017

\section{SLinked}

- http://dx.doi.org/10.1136/ sextrans-2017-053292

\section{Check for updates}

To cite: Mathews $C$ Kalichman MO, Laubscher $\mathrm{R}$, et al. Sex Transm Infect 2018:94:144-150.

\section{ABSTRACT}

Objectives We aimed to identify individual and sexual partnership characteristics associated with partner notification (PN) among people with STI. We hypothesised that PN would be less likely in more casual sexual partnerships and in partnerships with intimate partner violence (IPV).

Methods We conducted an observational study among the first 330 patients with STI enrolled in a trial of a behavioural intervention to reduce STI incidence, at a clinic in a poor, Cape Town community. We included 195 index patients (those reporting STI symptoms), and conducted longitudinal analyses using participantcompleted questionnaires on the day of diagnosis and 2 weeks later. Using partnership data for five recent sexual partners, we assessed factors associated with reported PN with logistic regressions, adjusting for repeated measurements on the same participant for each partner.

Results The sample included 99 males with 303 partners and 96 females with 158 partners. Males reported perpetrating IPV in $46.2 \%$ of partnerships. Females reported being IPV victims in $53.2 \%$ of partnerships. Males notified $58.1 \%$, females $75.4 \%$ of partners during the 2 weeks following diagnosis. Type of partner was an independent correlate of PN for males and females, with the odds of PN lower in more casual partnerships. For males, reporting physical IPV perpetration in the partnership was an independent correlate of PN. For females, there was no association between IPV victimisation in a partnership and PN.

Conclusions Efforts to decrease the pool of infectious partners need to have a strong focus on the promotion of PN in casual relationships and one-night stands. IPV was not identified as a barrier to PN. In future, we need to investigate the association between IPV with an objective measure of PN success such as partner testing or treatment, or index patient reinfection.

Clinical trial registration PACTR201606001682364; Pre-results.

\section{BACKGROUND}

Partner notification (PN) is a process by which a person with a STI informs sexual partners of their possible exposure and the need to be tested or to obtain treatment. $\mathrm{PN}$ is designed to interrupt STI transmission through the identification and treatment of undiagnosed infections. STI PN and treatment services are essential to prevent re-infection of index patients and to decrease the pool of infectious partners. People with STIs other than HIV in settings of high HIV prevalence, such as South Africa, are among the highest risk populations for HIV infection because STIs are among the most significant factors that facilitate HIV transmission. ${ }^{12} \mathrm{PN}$ and treatment are critical to the success of HIV prevention. Unfortunately, current methods of PN only reach a small proportion of partners. ${ }^{34}$ For example, among women in low/middle-income countries diagnosed with HIV, rates of non-disclosure of their HIV status to partners vary between $16 \%$ and $86 \%$ across studies. ${ }^{5}$

Most studies investigating barriers to $\mathrm{PN}$ have focused on index patients as the unit of analysis. ${ }^{6}$ Sexual risk behaviours vary between individuals and across an individual's sexual relationships. Studies have shown that condom use varies more across an individual's partnerships than between individuals. ${ }^{7}$ PN behaviours might vary across an individuals' partnerships. Investigations of the barriers to $\mathrm{PN}$ based on partnership-level data could inform interventions to promote PN tailored to the varying circumstances of index patients' sexual partnerships.

There is evidence that the success of PN varies by relationship type ${ }^{68}$ with PN being less likely to occur in more casual partnerships. People report reluctance to disclose fearing that abandonment and intimate partner violence (IPV) will be consequences of PN. ${ }^{5910}$ However, we know little about whether the presence of IPV in a relationship is a barrier to disclosure and PN. For women, IPV victimisation has been shown to be associated with incident HIV and HIV risk behaviours in some high prevalence settings, ${ }^{11}{ }^{12}$ and it is conceivable that IPV victimisation will be a barrier to notifying partners of an STI. For males, IPV perpetration has been associated with engaging in a cluster of sexual risk behaviours linked to an ideology of successful masculinity, ${ }^{13} 14$ and men who perpetrate IPV might be less likely to notify partners of an STI.

We aimed to identify the individual and sexual partnership characteristics associated with PN among people diagnosed with an STI, using longitudinal partnership-level data. We hypothesised that PN would be less likely in sex partnerships that were more casual, and in which the index 
Table 1 Characteristics of participants and partnerships associated with STI partner notification 2 weeks after the baseline survey: prospective analysis (crude ORs)

\begin{tabular}{|c|c|c|c|c|c|c|c|c|}
\hline & \multicolumn{4}{|c|}{ Males } & \multicolumn{4}{|c|}{ Females } \\
\hline & \multicolumn{2}{|c|}{ Partner notified 2 weeks after diagnosis } & \multirow[t]{2}{*}{$\mathrm{OR}^{*}$} & \multirow[t]{2}{*}{$95 \% \mathrm{Cl}$} & \multicolumn{2}{|c|}{$\begin{array}{l}\text { Partner notified } 2 \text { weeks after } \\
\text { diagnosis }\end{array}$} & \multirow{2}{*}{$\frac{\mathrm{OR}^{*}}{\%}$} & \multirow[t]{2}{*}{$95 \% \mathrm{Cl}$} \\
\hline & $\mathrm{n}$ & $\%$ & & & $\mathrm{n}$ & & & \\
\hline \multicolumn{9}{|l|}{ Characteristics of participants } \\
\hline \multicolumn{9}{|l|}{ Age } \\
\hline 24 years or younger & 58 & 48.33 & 1.00 & & 48 & 64.86 & 1.00 & \\
\hline Older than 24 years & 118 & 64.48 & 1.94 & 1.00 to 3.78 & 71 & 84.52 & 2.96 & 1.26 to 6.97 \\
\hline \multicolumn{9}{|l|}{ Education } \\
\hline Not completed grade 12 & 105 & 62.13 & 1.00 & & 82 & 75.23 & 1.00 & \\
\hline Completed grade 12 & 30 & 53.57 & 0.70 & 0.36 to 1.39 & 30 & 85.71 & 1.98 & 0.71 to 5.50 \\
\hline Post-grade 12 education & 41 & 52.56 & 0.68 & 0.30 to 1.52 & 7 & 50.00 & 0.33 & 0.11 to 0.99 \\
\hline \multicolumn{9}{|l|}{ STI symptoms: ulcer } \\
\hline No & 137 & 57.81 & 1.00 & & 102 & 73.91 & 1.00 & \\
\hline Yes & 39 & 59.09 & 1.05 & 0.49 to 2.25 & 17 & 85.00 & 2.00 & 0.58 to 6.91 \\
\hline \multicolumn{9}{|l|}{ STI symptoms: discharge } \\
\hline No & 76 & 63.33 & 1.00 & & 35 & 71.43 & 1.00 & \\
\hline Yes & 100 & 54.64 & 0.70 & 0.35 to 1.38 & 84 & 77.06 & 1.34 & 0.54 to 3.36 \\
\hline \multicolumn{9}{|l|}{ STI symptoms: burning urine } \\
\hline No & 47 & 59.49 & 1.00 & & 43 & 78.18 & 1.00 & \\
\hline Yes & 129 & 57.59 & 0.92 & 0.45 to 1.91 & 76 & 73.79 & 0.79 & 0.34 to 1.80 \\
\hline \multicolumn{9}{|l|}{ HIV status, participant report } \\
\hline Negative or unknown & 154 & 57.89 & 1.00 & & 84 & 79.25 & 1.00 & \\
\hline Positive & 22 & 59.46 & 1.07 & 0.36 to 3.19 & 35 & 67.31 & 0.54 & 0.23 to 1.27 \\
\hline Alcohol use, past 3 months & & & & & & & & \\
\hline Non-drinkers & 23 & 74.19 & 1.00 & & 29 & 80.56 & 1.00 & \\
\hline Drinkers & 45 & 47.37 & 0.31 & 0.09 to 1.07 & 42 & 75.00 & 0.72 & 0.22 to 2.44 \\
\hline Heavy drinkers & 108 & 61.02 & 0.54 & 0.17 to 1.74 & 48 & 72.73 & 0.64 & 0.20 to 2.12 \\
\hline Drug use past 3 months & & & & & & & & \\
\hline No & 84 & 51.22 & 1.00 & & 111 & 76.55 & 1.00 & \\
\hline Yes & 92 & 66.19 & 1.86 & 0.97 to 3.59 & 8 & 61.54 & 0.49 & 0.18 to 1.30 \\
\hline Characteristics of partnerships & & & & & & & & \\
\hline Age differential & & & & & & & & \\
\hline Participant younger & 104 & 65.00 & 1.89 & 1.09 to 3.26 & 13 & 81.25 & 1.06 & 0.28 to 3.98 \\
\hline Similar age & 56 & 49.56 & 1.00 & & 45 & 80.36 & 1.00 & \\
\hline Participant older & 16 & 53.33 & 1.16 & 0.48 to 2.80 & 61 & 70.93 & 0.60 & 0.30 to 1.17 \\
\hline Type of sex partner & & & & & & & & \\
\hline Once-off & 29 & 43.28 & 1.00 & & 6 & 42.86 & 1.00 & \\
\hline Casual & 63 & 48.46 & 1.23 & 0.65 to 2.34 & 26 & 57.78 & 1.82 & 0.39 to 8.48 \\
\hline Main & 84 & 79.25 & 5.00 & 2.60 to 9.63 & 87 & 87.88 & 9.67 & 2.02 to 46.35 \\
\hline Transactional sex & & & & & & & & \\
\hline No & 133 & 58.33 & 1.00 & & 103 & 75.18 & 1.00 & \\
\hline Yes & 43 & 57.33 & 0.96 & 0.44 to 2.10 & 16 & 76.19 & 1.06 & 0.36 to 3.13 \\
\hline Victim of physical IPV, past $3 \mathrm{mc}$ & & & & & & & & \\
\hline No & & & & & 78 & 72.22 & 1.00 & \\
\hline Yes & & & & & 41 & 82.00 & 1.75 & 0.82 to 3.76 \\
\hline Victim of sexual IPV, past 3 mon & & & & & & & & \\
\hline No & & & & & 81 & 75.00 & 1.00 & \\
\hline Yes & & & & & 38 & 76.00 & 1.06 & 0.49 to 2.26 \\
\hline Victim of emotional IPV, past 3r & & & & & & & & \\
\hline No & & & & & 72 & 71.29 & 1.00 & \\
\hline Yes & & & & & 47 & 82.46 & 1.89 & 0.87 to 4.14 \\
\hline Perpetrator of physical IPV, past & & & & & & & & \\
\hline No & 103 & 50.99 & 1.00 & & & & & \\
\hline Yes & 73 & 72.28 & 2.51 & 1.43 to 4.38 & & & & \\
\hline Perpetrator of sexual IPV, & & & & & & & & \\
\hline No & 143 & 56.75 & 1.00 & & & & & \\
\hline Yes & 33 & 64.71 & 1.40 & 0.70 to 2.78 & & & & \\
\hline Perpetrator of emotional IPV, pa & & & & & & & & \\
\hline No & 110 & 52.63 & 1.00 & & & & & \\
\hline Yes & 66 & 70.21 & 2.12 & 1.15 to 3.91 & & & & \\
\hline
\end{tabular}

*ORs are adjusted for clustering.

IPV, intimate partner violence. 
patient was an IPV victim. We also examined the association between PN and other participant and partnership characteristics, including participant age, education, alcohol and drug use, age disparity in the partnership and transactional sex. These characteristics have been associated with STI incidence and risk behaviour. ${ }^{15-19}$ Finally, we investigated the prevalence of adverse partner responses to PN such as IPV.

\section{METHODS}

We conducted an observational study among the first 330 patients with STI enrolled in a trial of a behavioural intervention to reduce STI incidence, at a clinic in a poor, Cape Town community. In longitudinal analyses, we examined factors associated with PN during the 2 weeks following diagnosis.

We invited all people 18 years of age and older who were diagnosed with an STI at the clinic to participate in the trial. They were recruited on the day of their STI diagnosis, and could participate that day, or at most 2 days afterwards. After recruiting the first 330 trial participants, we had an armed robbery, which led us to change from electronic to paper questionnaires. In the process, we reduced the length of the questionnaire, removing the IPV questions. This determined the sample size for this study. To limit the sample to 'index patients' and to exclude participants who had attended the clinic because they were a partner of someone with an STI, we excluded those who reported they did not have STI symptoms on the day of their clinic visit (discharge or unexplained fluid from genitals, open sore on genitals, or burning/pain on urination), and those who reported that their partners were already enrolled in the study (seven participants). Our analytic sample comprised 201 participants.

After consenting, participants completed the baseline questionnaire. A data collector asked participants to identify, by first name or nickname, up to five sex partners during the prior 3 months. Names were entered into an electronic questionnaire on a tablet computer, and participants self-completed the audio-assisted survey, in English or isiXhosa. We programmed questions about a partnership to include the partner name in the question wording. After the baseline survey, we randomly allocated participants to one of three single-session counselling interventions focusing on sexual risk behaviour and PN (the trial is not the subject of the current manuscript). After the counselling session, we invited participants to return to the clinic for a survey 2 weeks later.

\section{Measures}

The dependent variable, PN, was dichotomous: participant reports at the 2-week follow-up survey of whether the partner was notified by any method (in person, by phone or text message, or with a health worker's help) or if the participant had advised the partner to go for STI testing or treatment. If the partner had been notified, we asked how he/she had reacted.

At baseline, we asked participants their age, sex, education, STI symptoms, HIV status, alcohol and drug use. Participants were classified into non-drinkers, drinkers (drank between one and six drinks per occasion) and heavy drinkers (drank seven to nine drinks per occasion monthly or more frequently). If they used any of the following drugs in the three prior months, they were classified as drug users: marijuana, Mandrax, cocaine, methamphetamine or any drug injected with a needle.

At baseline, participants reported up to five sexual partners in the past 3 months, and they classified each as 'main', 'casual' or 'one-night stand' (casual partner referred to 'someone you have sex with on a regular basis who is not a main partner'; a one-night stand referred to 'someone who you may have only had sex with once or twice, not someone you have sex with on a regular basis'). Female participants were classified as an IPV victim in a partnership if they reported at baseline physical IPV (partner threw something at you which could hurt; hit you; threatened to use, or used a gun, knife or other weapon), emotional IPV (partner insulted you, made you feel bad about yourself or humiliated you; did something to scare or intimidate you on purpose) or sexual IPV (partner forced you to have sex when you did not want to; you had sex because you were scared of what partner might do if you said no) in the prior 3 months. Male partners were classified as IPV perpetrators if they reported at baseline perpetrating the above-mentioned forms of violence (except that male sexual IPV perpetration only included one item, 'forced partner to have sex when she did not want to'). We calculated the age differential between the participant and partner. A participant was classified as having engaged in transactional sex if, in the past 3 months, they had had sex with the partner in expectation of money or goods.

\section{Analysis}

Partnerships were the unit of analysis. We used a cluster analysis to adjust the SE to account for correlations arising from repeated measurements for the same participant (for each partner). We stratified the analyses by gender, and described the association of participant and partnership characteristics with PN. The analyses were longitudinal, using variables collected at baseline as independent variables and the dependent variable (PN) measured 2 weeks after baseline. We performed logistic regressions, reporting ORs and 95\% CIs. Because the participants were enrolled in an randomised controlled trial (RCT) and were exposed to one of three single-session behavioural counselling sessions after baseline, we included allocation assignment as a variable in the multivariate regression model. Statistical significance was defined as $\mathrm{P}<0.05$.

\section{RESULTS}

The first 330 participants enrolled in the trial comprised $62.5 \%$ of all patients with STI eligible to participate in the trial. Those who declined participation did so mostly due to time constraints. We excluded 45 participants because they were enrolled in the study more than 1 day their STI diagnosis. We excluded a further 84 participants because they did not report STI symptoms or they were a partner of someone already enrolled. The sample included 201 symptomatic participants (100 males and 101 females) who sought STI treatment between June 2014 and May 2015, and who had consented to participate in the parent study (trial). By the 2-week survey, we had retained 195 participants (97.0\%) (99 males and 96 females), and these comprise the analytic sample. Most 155 (79.5\%) were enrolled on the day of their STI diagnosis. The average age of males was 28.6 years (SD 7.23) and females 29.2 years (SD 7.73). Males reported an average of 3.1 partners for a total of 303 partners (106 main, 130 casual and 67 one-night stands) in the 3 months prior to baseline; females reported on average 1.6 partners for a total of 158 partners (99 main, 45 casual and 14 one-night stands).

Males reported IPV perpetration in 140 (46.2\%) partnerships. Males reported perpetrating physical IPV in 101 (33.3\%) partnerships, sexual IPV in $51(16.8 \%)$ and emotional IPV in 94 (31.0\%) partnerships. Males reported perpetrating IPV in 64 (60.4\%) main partnerships, 57 (43.9\%) casual partnerships and $19(28.4 \%)$ one-night stands. 
Table 2 Multivariate model of participant and partnership characteristics associated with notifying partner 2 weeks after baseline survey (prospective model)

\begin{tabular}{|c|c|c|c|c|}
\hline & \multicolumn{2}{|l|}{ Males } & \multicolumn{2}{|l|}{ Females } \\
\hline & Adjusted $\mathrm{OR}^{*}$ & $95 \% \mathrm{Cl}$ & Adjusted OR* & $95 \% \mathrm{Cl}$ \\
\hline \multicolumn{5}{|l|}{ Characteristics of participants } \\
\hline \multicolumn{5}{|l|}{ Age } \\
\hline 24 years or younger & 1.00 & & 1.00 & \\
\hline Older than 24 years & 1.34 & 0.59 to 3.03 & 1.49 & 0.61 to 3.62 \\
\hline \multicolumn{5}{|l|}{ Education } \\
\hline Not completed grade 12 & 1.00 & & 1.00 & \\
\hline Completed grade 12 & 1.10 & 0.47 to 2.60 & 0.97 & 0.21 to 4.42 \\
\hline Post-grade 12 education & 0.78 & 0.32 to 1.95 & 0.23 & 0.06 to 0.85 \\
\hline \multicolumn{5}{|l|}{ STI symptoms: ulcer } \\
\hline No & 1.00 & & 1.00 & \\
\hline Yes & 0.36 & 0.11 to 1.12 & 1.34 & 0.24 to 7.40 \\
\hline \multicolumn{5}{|l|}{ STI symptoms: discharge } \\
\hline No & 1.00 & & 1.00 & \\
\hline Yes & 0.62 & 0.29 to 1.33 & 1.28 & 0.35 to 4.72 \\
\hline \multicolumn{5}{|l|}{ STI symptoms: burning urine } \\
\hline No & 1.00 & & 1.00 & \\
\hline Yes & 0.62 & 0.21 to 1.84 & 1.25 & 0.44 to 3.59 \\
\hline \multicolumn{5}{|l|}{ HIV status, participant report } \\
\hline Negative or unknown & 1.00 & & 1.00 & \\
\hline Positive & 1.13 & 0.32 to 3.99 & 0.35 & 0.15 to 0.82 \\
\hline \multicolumn{5}{|l|}{ Alcohol use, past 3 months } \\
\hline Non-drinkers & 1.00 & & 1.00 & \\
\hline Drinkers & 0.14 & 0.04 to 0.50 & 1.27 & 0.34 to 4.78 \\
\hline Heavy drinkers & 0.30 & 0.09 to 1.02 & 1.66 & 0.46 to 6.01 \\
\hline \multicolumn{5}{|l|}{ Drug use past 3 months } \\
\hline No & 1.00 & & 1.00 & \\
\hline Yes & 3.04 & 1.48 to 6.26 & 0.49 & 0.08 to 2.91 \\
\hline \multicolumn{5}{|l|}{ Characteristics of partnerships } \\
\hline \multicolumn{5}{|l|}{ Age differential } \\
\hline Participant younger & 2.02 & 1.06 to 3.85 & 1.19 & 0.09 to 15.26 \\
\hline Similar age & 1.00 & & 1.00 & \\
\hline Participant older & 1.67 & 0.69 to 4.04 & 0.70 & 0.31 to 1.55 \\
\hline \multicolumn{5}{|l|}{ Type of sex partner } \\
\hline Once-off & 1.00 & & 1.00 & \\
\hline Casual & 1.17 & 0.54 to 2.55 & 1.94 & 0.51 to 7.43 \\
\hline Main & 5.18 & 2.37 to 11.33 & 20.41 & 4.64 to 89.72 \\
\hline \multicolumn{5}{|l|}{ Transactional sex } \\
\hline No & 1.00 & & 1.00 & \\
\hline Yes & 0.73 & 0.28 to 1.95 & 2.98 & 0.84 to 10.59 \\
\hline \multicolumn{5}{|c|}{ Victim of physical IPV, past 3 months } \\
\hline No & & & 1.00 & \\
\hline Yes & & & 0.48 & 0.11 to 2.19 \\
\hline \multicolumn{5}{|c|}{ Victim of sexual IPV, past 3 months } \\
\hline No & & & 1.00 & \\
\hline Yes & & & 0.49 & 0.15 to 1.58 \\
\hline Victim of emotional IPV, pas & & & & \\
\hline No & & & 1.00 & \\
\hline Yes & & & 1.75 & 0.38 to 7.99 \\
\hline Perpetrator of physical IPV, & & & & \\
\hline No & 1.00 & & & \\
\hline Yes & 2.22 & 1.00 to 4.93 & & \\
\hline Perpetrator of sexual IPV, pa & & & & \\
\hline No & 1.00 & & & \\
\hline Yes & 1.26 & 0.49 to 3.22 & & \\
\hline Perpetrator of emotional IPI & & & & \\
\hline No & 1.00 & & & \\
\hline Yes & 0.85 & 0.39 to 1.86 & & \\
\hline
\end{tabular}

*ORs are adjusted for all other factors in the model, for clustering, and for trial condition.

IPV, intimate partner violence. 
Females reported IPV victimisation in 84 (53.2\%) partnerships. Females reported physical IPV in 50 (31.7\%) partnerships, sexual IPV in $50(31.7 \%)$ and emotional IPV in 57 (36.1\%) relationships. Females reported being a victim of IPV in $67(67.7 \%)$ main partnerships, $17(37.8 \%)$ casual partnerships and $0(0 \%)$ one-night stands.

Males notified 176 (58.1\%) partners and females notified 119 (75.4\%) partners during the 2 weeks following diagnosis.

Table 1 presents participant and partnership characteristics by PN during the 2 weeks following diagnosis. Among males, the odds of PN were higher when the participant was over 24 years; when they were more than 3 years younger than their partner (compared with same age); when it was a main partnership; and when they reported perpetrating physical and emotional IPV in the partnership. Among females, the odds of PN where higher when the participant was over 24 years; when they had not completed grade 12 (compared with having post-grade 12 education); and when it was a main partnership.

Table 2 shows results of the multivariate models of factors associated with partner notification during the 2 weeks after diagnosis. Among males, adjusting for all other factors in the model, the odds of PN were higher in non-drinkers (compared with drinkers), in drug users, in main partnerships (compared with one-night stands), and in partnerships where the participant was younger than the partner and the participant reported perpetrating physical IPV. Among females, the odds of were PN higher among participants who had not completed grade 12 (compared with post-grade 12 education), among participants who reported being HIV negative/unknown HIV status and in main partnerships (vs one-night stands).

Male participants reported the following partner reactions to PN: violence, 16 (4.4\%) partners; abandonment (partner told me to leave and did not want to see me again), 23 (6.3\%); anger, 51 (14.0\%); caring, 68 (18.7\%); appreciation, 121 (33.2\%); no reaction, $45(12.4 \%)$. Females reported violent reactions, 2 (0.9\%) partners; abandonment, 7 (3.3\%); anger, 11 (5.1\%); caring, 54 (25.2\%); appreciation, 68 (31.8\%); and $36(16.8 \%)$ did not react. Participants could report one or more reactions per partner.

\section{DISCUSSION}

The strongest, independent correlate of PN was partner type. Male and female participants were more likely to notify their main partners compared with their one-night stands. Participants were somewhat more likely to notify casual partners compared with one-night stands although the association was not statistically significant. These findings are consistent with most other studies. ${ }^{6}$ In other research, however, there is not a consistent association between more serious partnerships and behaviour that protects partners against STIs. For example, the prevalence of condomless sex is more common in more serious (vs casual) relationships. 72021

The participants reported high levels of IPV: over 50\% of women reported IPV victimisation and almost 50\% of men reported IPV perpetration. Our hypothesis that PN would be less likely in partnerships with IPV was not supported. Among men, physical IPV perpetration was an independently positively associated with PN. This could suggest that men who perpetrate physical IPV in a partnership are less likely that those who do not perpetrate such IPV to fear the consequences of PN. These findings show that IPV was not a barrier to self-reported PN. However, it is possible that IPV undermines successful PN outcomes in other ways. For example, IPV might undermine a partner's ability to access STI diagnosis and treatment services.

Our findings are consistent with a survey conducted in US family planning clinics among young women who had ever had an STI: those exposed to IPV were no more or less likely to have notified their partner. ${ }^{10}$ If we regard $\mathrm{PN}$ as a behaviour that has the potential to mitigate STI risk, our findings are in contradiction to those of other studies which IPV leads to behaviours that put partners at greater risk of STIs. ${ }^{13}{ }^{20}$ However, the study by Decker et al suggests that there might be other ways in which IPV undermines successful PN. Partners of women who had experienced IPV were less likely to subsequently seek care for their STIs, ${ }^{10}$ reinforcing the importance of investigating the association between IPV and successful PN outcomes such as partner treatment and index patient reinfection.

Given the prevalence of IPV reported by the participants in this study, it is surprising that so few of them reported violence as a consequence of PN. Yet, it is of concern that there were some reports of violence and abandonment. Interventions to facilitate safer disclosure of STIs might prevent these harmful consequences of PN; however, there is little evidence about what such interventions might look like. ${ }^{22}$ The rates of IPV as a consequence of disclosure are similar to those described in other studies. $^{5} 10$

Males were more likely to notify their partner when they were more than 3 years younger than their partner, compared with similar age. Age disparity, when the woman is younger than her male partner, has been hypothesised as an indicator of relationship power inequity and a risk factor for STI, ${ }^{23}$ but our findings do not bear this out. We found no evidence that transactional sex impedes PN. This contrasts to other studies with dyad-level analyses, showing that economic dependence on a partner is associated with sexual risk behaviours. ${ }^{20} 21$

Individual-level factors associated $\mathrm{PN}$ included education and reported HIV status among women, and drug and alcohol use among men. Compared with female participants who had not completed grade 12 , those with post-grade 12 education were less likely to notify partners. This is unexpected, given that more educated individuals tend to be early adopters of safer sexual behaviours. ${ }^{15}$ Women who reported they were HIV positive were less likely to notify partners compared with those who reported they were HIV negative or of unknown status. These participants might be at higher risk of transmitting infections, and it is critical to focus PN efforts on them. Male alcohol drinkers were less likely to notify partners, compared with non-drinkers, which is consistent with literature demonstrating that alcohol is a risk factor for HIV acquisition and further transmission. ${ }^{24}$ Men who reported that they used drugs were more likely than those who did not to notify partners. This is an unexpected finding given that drug use is associated with sexual risk behaviours. ${ }^{25}$ Whether drug use interferes with successful PN outcomes such as partner treatment and index patient reinfection needs further investigation.

\section{Limitations}

We are unable to determine the accuracy of our assumption that symptomatic participants were 'index cases' and were not attending the clinic because they were referred by a partner. In the baseline survey, we did not ask whether they had been referred by a partner, and the patient electronic records do not discriminate between index patients and partners. A minority of participants were enrolled 1 day after their diagnosis which might have led to an underestimate of PN. In a sensitivity 


\section{Key messages}

- STI partner notification (PN) is less likely in casual compared with main partnerships, and efforts to promote PN need to focus on casual relationships.

- Male patients with STI had been a perpetrator of intimate partner violence (IPV), and females an IPV victim in approximately half of their recent sexual partnerships.

- This study does not provide any evidence that IPV is a barrier to PN based on participants' reports.

- Harmful consequences of PN, abandonment and IPV, were reported in under $10 \%$ of notifications, suggesting the appropriateness of interventions to facilitate safer disclosure of STIs.

analysis (not reported here), we excluded those not enrolled on the day of their diagnosis, and there were no substantial differences in the estimates or the interpretation of the findings. PN was self-reported, and not validated with an objective measure such as partner visits to STI clinics or index patient reinfection. We did not explore the relationship between male IPV victimisation and PN (nor female perpetration and PN). We speculated the harmful effects of victimisation would be more relevant to female patients with STI, given the prevalence of intimate partner homicide, the most severe form of IPV, is far more common in females compared with males (39\% of female homicides were perpetrated by intimate partners vs only $6 \%$ of male homicides). ${ }^{26}$

\section{CONCLUSIONS}

This study shows the individual and partnership-level dynamics influencing PN, and the findings can inform interventions to promote PN. PN is much more likely to occur in the context of main partnerships. This means efforts to decrease the pool of infectious partners need to focus on the promotion of $\mathrm{PN}$ in casual relationships and one-night stands. On average, successful PN needs to be achieved with more than one partner per index case to prevent onward transmission ${ }^{4}$ and PN successes with casual or ex-regular partners are more efficient at preventing onward transmission relative to successes with regular partners. ${ }^{4}$ Despite the high levels of IPV in partnerships of patients with STI in this setting, our study does not provide evidence that IPV is a barrier to PN measured by participants' reports. In future, we need to investigate the association between IPV and an objective measure of PN success such as partner testing, treatment or index patient reinfection.

\section{Handling editor Jackie A Cassell}

Acknowledgements We thank Sekelwa Dumile, Amanda Mdlikiva, Brenda Skonje and Thembinkosi Mdlikiva for collecting the data; Tamar Grebler for programming the electronic questionnaire; Carl Lombard for guidance on the statistical analysis, Karen Jennings, Koena Nkoko and Lindiwe Matebeni for supporting research in the public health services they manage; and the clinicians who referred their patients to participate in our study.

Contributors CM, SCK and MOK conceptualised the study. MOK, SCK, CM, KN and $\mathrm{ML}$ contributed to the acquisition of data for the study. RL and $\mathrm{CH}$ performed the statistical analyses. CM drafted the manuscript. All authors contributed to revising it and approved the final version.

Funding This research was supported by a grant from the National Institute of Health under award number R01HD074560. This research was also supported by funding from the South African Medical Research Council.

Competing interests None declared.
Ethics approval The study was approved by the Ethics Committee of the South African Medical Research Council (EC018-10/2013) and the University of Connecticut Institutional Review Board (H12-340).

Provenance and peer review Not commissioned; externally peer reviewed.

Open Access This is an Open Access article distributed in accordance with the Creative Commons Attribution Non Commercial (CC BY-NC 4.0) license, which permits others to distribute, remix, adapt, build upon this work non-commercially, and license their derivative works on different terms, provided the original work is properly cited and the use is non-commercial. See: http://creativecommons.org/ licenses/by-nc/4.0/

(c) Article author(s) (or their employer(s) unless otherwise stated in the text of the article) 2018. All rights reserved. No commercial use is permitted unless otherwise expressly granted.

\section{REFERENCES}

1 Boily MC, Baggaley RF, Wang L, et al. Heterosexual risk of HIV-1 infection per sexual act: systematic review and meta-analysis of observational studies. Lancet Infect Dis 2009;9:118-29.

2 Royce RA, Seña A, Cates W, et al. Sexual transmission of HIV. N Engl J Med 1997:336:1072-8

3 Ferreira A, Young T, Mathews C, et al. Strategies for partner notification for sexually transmitted infections, including HIV. Cochrane database of syst rev 2013:10:Cd002843.

4 Althaus CL, Turner KM, Mercer CH, et al. Effectiveness and cost-effectiveness of traditional and new partner notification technologies for curable sexually transmitted infections: observational study, systematic reviews and mathematical modelling. Health Technol Assess 2014;18:1-100.

5 Medley A, Garcia-Moreno C, McGill S, et al. Rates, barriers and outcomes of HIV serostatus disclosure among women in developing countries: implications for prevention of mother-to-child transmission programmes. Bull World Health Organ 2004;82:299-307.

6 Alam N, Chamot E, Vermund SH, et al. Partner notification for sexually transmitted infections in developing countries: a systematic review. BMC Public Health 2010;10:19.

7 Mustanski B, Newcomb ME, Clerkin EM. Relationship characteristics and sexual risk taking in young men who have sex with men. Health Psychol 2011;30:597-605.

8 Rayment M, Curtis H, Carne C, et al. An effective strategy to diagnose HIV infection: findings from a national audit of HIV partner notification outcomes in sexual health and infectious disease clinics in the UK. Sex Transm Infect 2017;93:94-9.

9 Rujumba J, Neema S, Byamugisha R, et al. "Telling my husband I have HIV is too heavy to come out of my mouth": pregnant women's disclosure experiences and support needs following antenatal HIV testing in eastern Uganda. J Int AIDS SoC 2012;15:17429.

10 Decker MR, Miller E, McCauley HL, et al. Intimate partner violence and partner notification of sexually transmitted infections among adolescent and young adult family planning clinic patients. Int J STD AIDS 2011;22:345-7.

11 Jewkes RK, Dunkle K, Nduna M, et al. Intimate partner violence, relationship power inequity, and incidence of HIV infection in young women in South Africa: a cohort study. Lancet 2010:376:41-8.

12 Kouyoumdjian FG, Calzavara LM, Bondy SJ, et al. Intimate partner violence is associated with incident HIV infection in women in Uganda. AIDS 2013;27:1331-8.

13 Jewkes R, Sikweyiya Y, Morrell R, et al. The relationship between intimate partner violence, rape and HIV amongst South African men: a cross-sectional study. PLoS One 2011;6:e24256.

14 Kouyoumdjian FG, Findlay N, Schwandt M, et al. A systematic review of the relationships between intimate partner violence and HIVIAIDS. PLOS One 2013;8:e81044.

15 Hargreaves JR, Bonell CP, Boler T, et al. Systematic review exploring time trends in the association between educational attainment and risk of HIV infection in sub-Saharan Africa. AIDS 2008;22:403-14.

16 Ferreira-Borges C, Rehm J, Dias S, et al. The impact of alcohol consumption on African people in 2012: an analysis of burden of disease. Trop Med Int Health 2016;21:52-60.

17 Degenhardt L, Whiteford HA, Ferrari AJ, et al. Global burden of disease attributable to illicit drug use and dependence: findings from the Global Burden of Disease Study 2010. Lancet 2013;382:1564-74.

18 Piot P, Greener R, Russell S. Squaring the circle: AIDS, poverty, and human development. PLoS Med 2007:4:e314-5.

19 Maughan-Brown B, Evans M, George G. Sexual Behaviour of Men and Women within Age-Disparate Partnerships in South Africa: Implications for Young Women's HIV Risk. PLoS One 2016;11:e0159162.

20 Argento E, Shannon K, Nguyen P, et al. The role of dyad-level factors in shaping sexual and drug-related HIV/STI risks among sex workers with intimate partners. Drug Alcohol Depend 2015;157:166-73 


\section{Behaviour}

21 Marshall BD, Perez-Brumer AG, MacCarthy S, et al. Individual and Partner-Level Factors Associated with Condom Non-Use Among African American STI Clinic Attendees in the Deep South: An Event-Level Analysis. AIDS Behav 2016;20:1334-42.

22 Kennedy CE, Haberlen S, Amin A, et al. Safer disclosure of HIV serostatus for women living with HIV who experience or fear violence: a systematic review. J Int AIDS SoC 2015;18(Suppl 5):20292.

23 Harling G, Newell ML, Tanser F, et al. Do age-disparate relationships drive HIV incidence in young women? Evidence from a population cohort in rural KwaZulu-Natal, South Africa. J Acquir Immune Defic Syndr 2014;66:443-51.
24 Schneider M, Chersich M, Temmerman M, et al. The impact of alcohol on HIV prevention and treatment for South Africans in primary healthcare. Curationis 2014;37:1137.

25 Parry CD, Plüddemann A, Myers B, et al. Methamphetamine use and sexual risk behaviour in Cape Town, South Africa: a review of data from 8 studies conducted between 2004 and 2007. Afr J Psychiatry $2011 ; 14: 372-6$.

26 Stöckl H, Devries K, Rotstein A, et al. The global prevalence of intimate partner homicide: a systematic review. Lancet 2013;382:859-65. 